\title{
Characteristics of patients brought to the Paediatric Emergency Department (PED) by Ambulance at University Hospital Limerick (UHL)
}

\author{
Husnain Mahomed ${ }^{1}$, Shozab Ali Taq ${ }^{1}$, Abrar Hader ${ }^{1}$, Peter O'Reilly ${ }^{1}$, Roisin McNamara², \\ John Twomey ${ }^{1}$, Fionnuala Caufield ${ }^{2}$, Anne-Marie Murphy ${ }^{1}$
}

1. Department of Paediatrics, University Hospital Limerick, Limerick, Ireland

2. Paediatric Emergency Department - Children's University Hospital Temple Street, Dublin Ireland

\section{INTRODUCTION}

UHL PED has noticed an increase in ambulance referrals some of whom required non-urgent attention ( $<2$ hours ). We hoped to emulate a study by one of the tertiary level PEDs in Dublin, Ireland in order to review the characteristics of our own cohort of patients.

\section{AIMS}

To retrospectively review the characteristics of patients presenting to our PED in relation to their presenting complaint, urgency and outcome.

\section{METHODS}

Hospital Electronic databases were used to identify all patients who accessed our paediatric ED between 01.11.2017 and 31.01.2018. ED records were reviewed to ascertain patients brought in by ambulance (BIBA), their presenting complaint, urgency, and outcome.

\section{RESULTS}

From 01.11.17 to 31.01.18 4504 patients reviewed in UHL PED. $106(2 \%)$ were BIBA. $32(30 \%)$ with respiatory tract infections, $26(25 \%)$ with seizure activity, 12 (11\%) with head injuries, 7 $(6 \%)$ with limb injuries, $6(6 \%)$ with self harm/overdose, $4(4 \%)$ with syncope, $3(3 \%)$ with burns and 7 (6\%) other.

The most common presentations were pyrexia (30\%), seizures $77(25 \%)$ and injuries (18\%). Self harm/overdose comprised 6 (5\%). Of significance non-urgent presentations at 33 (29\%). 10 $(9.4 \%)$ required ambulance intervention.

\section{Triage Classification (Results)}

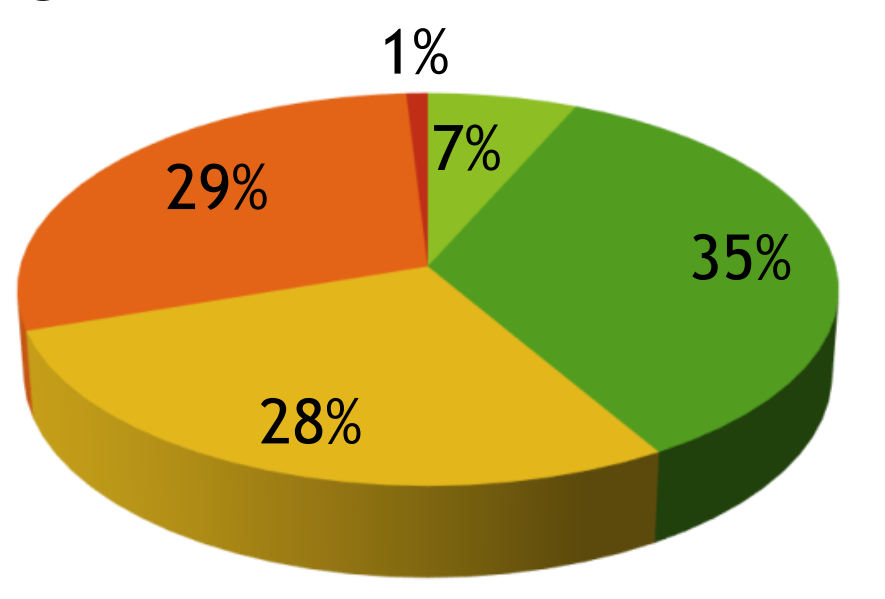

- Immediate

- Urgent $(<10$ minutes)

Semi-urgent $(<$ 1hour)

Non-urgent $(<2$ hours)

- Routine (> 2 hours)

\section{OUTCOMES}

$44 \%$ admitted

- $8(7.5 \%)$ transferred to tertiary Paediatric ICU

- Burn, Trauma, shunt review

- 9 (8.5\%) admitted to UHL Paediatric High Dependency unit $56 \%$ discharged home

- $72 \%$ of these were discharged with GP follow up recommended

No deaths during this study period

\section{CONCLUSION}

The most common presentations were pyrexia, injuries and seizures 77 (72\%), self harm/overdose comprised 6 (6\%).

Difficult to define inappropriate ambulance use

$56 \%$ of our cohort were discharged home with GP follow up

$29 \%$ required only non-urgent attention consistent with the previous study conducted by the Paediatric Emergency Department team in Temple Street Hospital (27\%)(Caufield et. al 2016)

\section{SOURCES}

Lightfoot Solutions UK Ltd, (2016). National Ambulance Service of Ireland emergency service baseline and capacity review. [online]www.hse.ie/eng/services/publications/NAScapacityreview .pdf[Accessed 3rd March. 2018].

Morgans, A. Burgess S. Judging a patient's decision to seek emergency healthcare: clues for managing increasing patient demand. Aust Health Rev. 2012 Feb;36(1):110-4.

\begin{tabular}{|l|l|l|}
\hline \multicolumn{3}{|l|}{ Presenting Complaints } \\
\hline Pyrexia (30\%) & Otitis Media & $\begin{array}{l}\text { Asthma } \\
\text { exacerbation }\end{array}$ \\
\hline Burns & Drowning & Head injury (11\%) \\
\hline Limb injury (6\%) & Seizure (25\%) & RTA \\
\hline Foreign body & DKA & Hypoglycaemia \\
\hline Burns (3\%) & Self-harm & Poisoning \\
\hline Croup & Neck pain & Vomiting \\
\hline Testicular Pain & Abdominal Pain & Wound \\
\hline Rash & Collapse & DSP (6\%) \\
\hline Anaphylaxis & Cough & ENT \\
\hline
\end{tabular}

